\title{
Differential diagnosis of myelopathy in a patient with relapsed acute lymphoblastic leukemia
}

\author{
Alexey Yu. Polushin ${ }^{1}$, Ksenia S. Afanasyeva ${ }^{1}$, Bella I. Ayubova ${ }^{1}$, Sergey N. Bardakov ${ }^{2}$, Dmitry I. Skulyabin ${ }^{2}$, \\ Andrey O. Agafonov ${ }^{1}$, Olga V. Sergiyenya ${ }^{3}$, Yaroslav B. Skiba ${ }^{1}$, Vladimir S. Krasnov ${ }^{1}$, Mikhail M. Kanunnikov ${ }^{1}$, \\ Tatiana A. Rudakova ${ }^{1}$, Anna G. Smirnova ${ }^{1}$, Sergey N. Bondarenko ${ }^{1}$, Maria D. Vladovskaya ${ }^{1}$, Ivan S. Moiseev ${ }^{1}$, \\ Alexander D. Kulagin ${ }^{1}$ \\ ${ }^{1}$ Pavlov University, St. Petersburg, Russia \\ ${ }^{2}$ S. M. Kirov Military Medical Academy, St. Petersburg, Russia \\ ${ }^{3}$ V. A. Almazov National Medical Research Center, St. Petersburg, Russia
}

$\begin{array}{ll}\text { Dr. Alexey Yu. Polushin, Pavlov University, 6-8 L. Tolstoy St, } & \text { Phone: +7 (911) } 8167559 \\ \begin{array}{ll}\text { 197022, St. Petersburg, Russia } & \text { E-mail: alexpolushin@yandex.ru }\end{array}\end{array}$

Citation: Polushin AY, Afanasyeva KS, Ayubova BI et al. Differential diagnosis of myelopathy in a patient with relapsed acute lymphoblastic leukemia. Cell Ther Transplant 2021; 10(2): 60-68.

\section{Summary}

Leukemia-associated myelopathy is a rare but still underestimated complication. It can be of different etiology, associated with both underlying disease and its specific treatment. It requires differential diagnosis with funicular myelosis, polyradiculoneuropathy, volumetric and hemorrhagic masses, vascular ischemia, dysmetabolic manifestations, as well as with adverse effects of intensive treatment of the primary disease using irradiation, cytostatic, targeted therapy, with paraneoplastic myelopathy and progression of the underlying disease. However, its diagnostics by neuroimaging techniques may proceed later than the onset of appropriate neurological symptoms.
We present a clinical case of myelopathy in a 31-year-old patient with acute lymphoblastic leukemia (ALL) which was confirmed by MRI of the spinal cord 2.5 months after the onset of neurological signs. The article presents diagnostic criteria for ALL-associated myelopathy.

\section{Keywords}

Neuroleukemia, acute lymphoblastic leukemia, allogeneic hematopoietic stem cell transplantation, neurological complications, myelopathy, MRI, differential diagnosis, targeted therapy.

\section{Introduction}

Advances in hematology, molecular biology, immunology and pharmaceutical industry have made potentially curable a number of fatal blood cancers, e.g., acute leukemias. Most patients with newly diagnosed acute lymphoblastic leukemia (ALL) achieve remission of the disease (up to 90\%) after cytostatic chemotherapy, and overall 5-year survival rate of young patients (up to 35 years) has reached $61 \%$. However, ALL, rather than acute myeloblastic leukemia (AML) is accomplished by specific damage of the central nervous system caused by blast cells. Thus, about $5 \%$ of patients with ALL show involvement of the central nervous system (CNS) with appropriate clinical manifestations, and relapse of the disease is accompanied by CNS affection in $30 \%$ of cases, as compared with $0.6-2.9 \%$ in AML patients $[1,2]$.

Given the high risk of neuroleukemia in ALL, polychemotherapy programs include intrathecal (endolumbal) combination therapy with methotrexate, cytarabine, and dexamethasone or prednisolone, along with craniospinal irradiation (CSI), together with intravenous administration of other cytostatic drugs. CSI and intrathecal administration of cytostatic drugs are included in modern polychemotherapy regimens and used both for prophylactic and therapeutic purposes.

Over the past two decades, this approach has led to higher rates of complete ALL remission and less common neurological 
relapses (up to 4\%) [3]. However, encephalopathy or polyneuropathy become more often in this cohort, manifesting as adverse effects of systemic chemotherapy, whereas frequency of myelopathy increases with intrathecal chemotherapy.

With regard to specific etiological factors, one may distinguish, e.g., autoimmune, infectious (including post-vaccinal), paraneoplastic, traumatic/compression, ischemic, toxic, post-radiation myelopathies. However, no generally accepted classification of myelopathies exists so far [4].

Acute demyelinating myelopathy following allogeneic hematopoietic stem cell transplantation (allo-HSCT) may be considered an autoimmune complication associated with immune reconstitution inflammatory syndrome (IRIS) affecting CNS [5]. However, myelopathy during treatment of leukemia is rare, and only some clinical observations are found in the literature, thus explaining lack of uniform diagnostics and management for this complication

Further on, we present a case of myelopathy developed in the course of ALL chemotherapy and repeated HSCT.

\section{Clinical case description}

Here is our observation of a 31-year-old male patient with relapsed ALL. In November 2014 (26 years old), he complained of back pain and general weakness. Upon blood check, the diagnosis of ALL was verified by the detection of $82 \%$ of blasts in bone marrow with immune phenotype of BII (common) ALL (-CD45low+CD34+/-CDHLA-DR, CD19+CD10+CD33-CD38 +/- CD20-CD14-CD7-CD13CD117-Cd4-). Cytogenetic data were not available upon primary diagnosis.

The first clinical hematological remission (CR) was achieved after two induction courses according to the $A L L-2009$ programmed therapy protocol [6] with prophylactic endolumbar injections (up to 16) of therapeutic triplets, i.e., methotrexate (15 mg), cytarabine (30 mg), dexamethasone (4 mg). The programmed therapy according to this protocol was continued until February 2018.

At control visit (August 2018), the first late isolated bone marrow relapse was diagnosed, as evidenced by $40 \%$ of blasts in the marrow samples. Therefore, re-induction chemotherapy was started again, according to the $A L L-2009$ protocol, resulting into second $\mathrm{CR}$, after two induction and two consolidation courses.

Due to relapsing course of the disease, the patient, having been in the second remission, was considered a candidate for allo-HSCT. However, when examined in April 2019, 76\% of blast cells were detected in bone marrow, with immune phenotype of ALL BII type, according to EGIL, with CD22 antigen expression in $83.4 \%$ of the blast population. Cytogenetic study revealed an aberrant clone with reciprocal translocation and chromosome 12 trisomy detected in 95\% of metaphases, an additional $\mathrm{t}(5 ; 6)$ reciprocal translocation was observed in 35\%; molecular biological studies did not reveal any specific mutations. Ultrasound scan revealed signs of testicular involvement, intra-abdominal lymphadenopathy, as well as cytosis of $23 / 3$ in cerebrospinal fluid (CSF), presented with cells similar to the blast immune profile, however, in the absence of neurological symptoms. Thus, a second early combined relapse was diagnosed in the patient with involvement of bone marrow, testicles, intra-abdominal lymph nodes and central nervous system.

Taking into account the relapsed disease with a known target antigen, two courses of therapy were performed using anti-CD22 antibody (inotuzumab ozogamicin) at a full dosage. During the therapy, several signs of hematological toxicity (grade 2 anemia, grade 3 neutropenia) and non-hematologic toxicity (febrile neutropenia) were noted. Endolumbar triplet therapy was performed (4 injections per course) as a part of neuroleukemia treatment, accomplished by a course of local radiation therapy to the scrotal area, at the total cumulated dose limited to $8 \mathrm{~Gy}$, due to the development of grade 4 neutropenia, with a positive clinical effect. The $3^{\text {rd }}$ CR was achieved in May 2019, after two courses of inotuzumab ozogamicin, as evidenced by CSF sanation, negativity for minimal residual disease (MRD), in absence of convincing data for the presence of extramedullary lesions.

Since the end of May 2019, the patient complained of increasing gait disturbance, weakness and numbness in the legs, atrophy of the leg muscles, dysfunction of pelvic organs presenting as inappropriate urination, constipation, increased signs of sensory ataxia and progressive weight loss (Fig. 1).

A week later, neurological examination showed clinical deterioration which manifested as palmar-chin (MarinescuRadovici's) symptom bilaterally; small postural tremor of the both hands (probably of toxic origin); signs of mixed lower paraparesis (moderate decrease in strength at the distal parts of both legs up to 4 points mRS), high tendon reflexes (mostly in the lower extremities); sensitive disorders up to the Th10 level along with polyneuropathy-like signs in the distal parts of the legs; decreased deep sensitivity in the distal parts of the legs; severe sensitive ataxia, pelvic dysfunction of central type. Symmetrical atrophy of femoral and calf muscles was also noted. Over the next 2 weeks, weakness in the lower extremities increased up to 2 points, acute urinary retention developed, thus requiring installation placement of a transurethral catheter. Treatment with anticholinesterase agents, thioctic acid, group B vitamins, exercise therapy were carried out, without significant clinical effect.

Due to recurrent course of the disease, allo-HSCT in third CR from HLA-compatible unrelated donor was decided to consolidate the remission state. With respect to severe comorbidity, primarily, due to neurological disorders, and heavy pre-treatment story, a non-myeloablative conditioning treatment was performed, including fludarabine and busulfan (8 mg/kg/course). On June 28, 2019 (D0), peripheral blood stem cells (PBSCs) were transfused to the recipient $\left(7.5 \times 10^{6} \mathrm{CD} 34+\right.$ cells $\left./ \mathrm{kg}\right)$. Graft-versus-host disease (GVHD) prophylaxis regimen included cyclophosphamide $(100 \mathrm{mg} / \mathrm{kg})$, tacrolimus, mycophenolate mofetil. After conditioning therapy and GVHD prophylaxis, the patient developed cytopenia, oral mucositis (grade 2), febrile neutropenia which responded to empiric antibiotic therapy. In the early posttransplant period $(D+33)$, there was worsening of neurological deficit manifesting with spread of muscle 


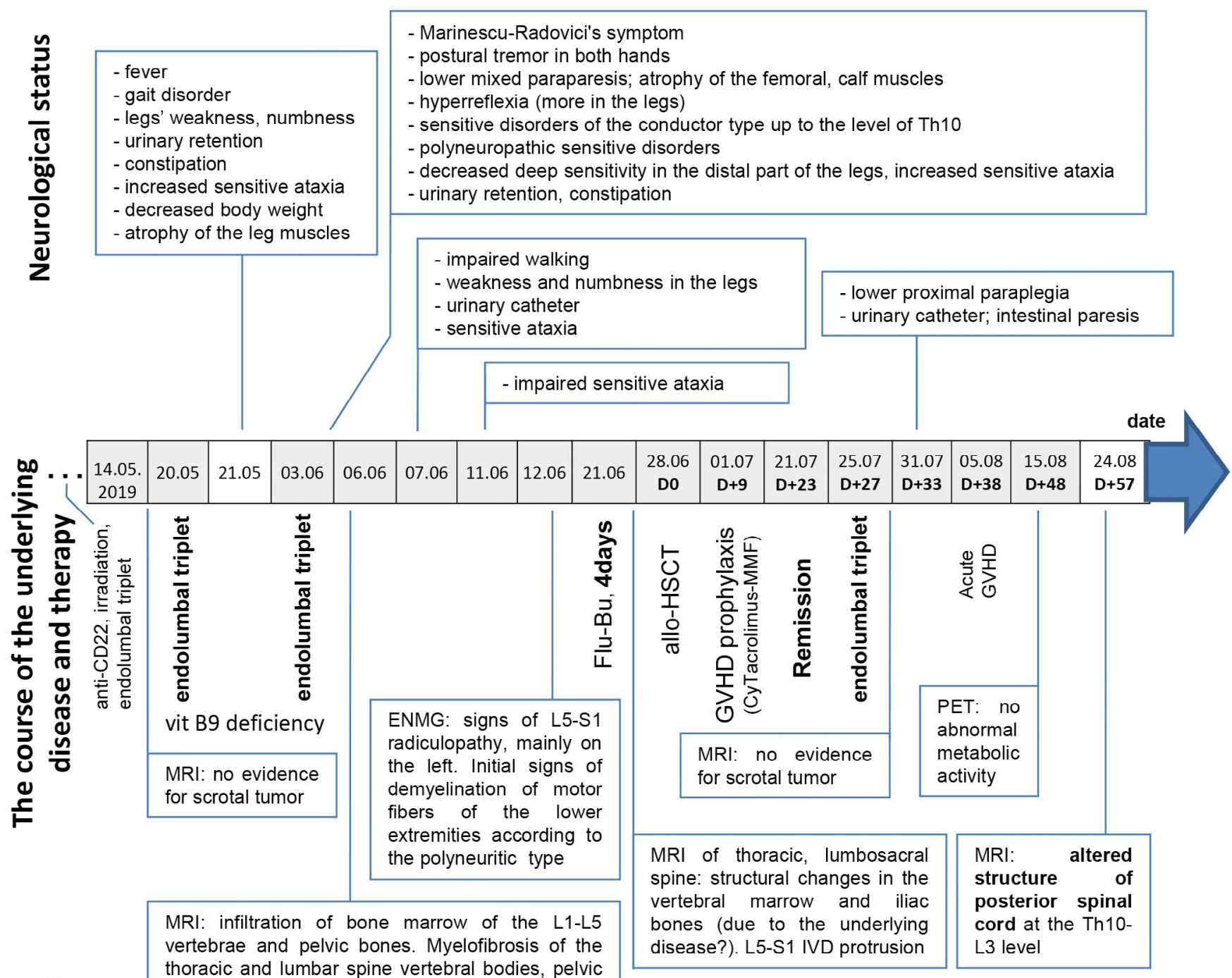

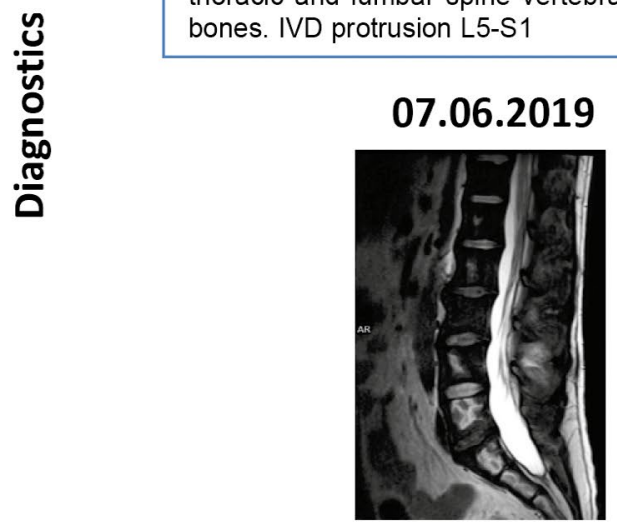

Sag T2-WI

\subsubsection{9}

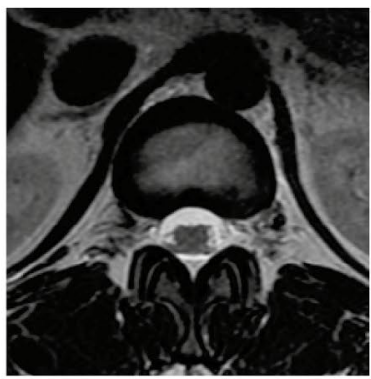

Ax T2-WI

\subsubsection{9}

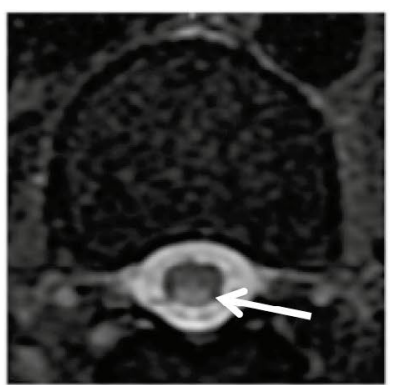

Ax T2-WI

FatSat

Figure 1. Time course of myelopathy upon anticancer therapy of ALL patient

Notations: $a G v H D$ - acute reaction "graft-versus-host disease; allo-HSCT - allogeneic hematopoietic stem cell transplantation; Ax - axilar; Bu - busulfan; Cy - cyclophosphamide; ENMG - electroneuromyography; Flu - fludarabin; IVD - intervertebral disc; PET - positron emission tomography; Sag - sagittal. 
weakness to the proximal parts of lower extremities and increased severity of amyotrophy, intestinal paresis.

Recovery of peripheral blood parameters (platelets $>20 \times 10^{9} / 1$, leukocytes $>1 \times 10^{9} / 1$, neutrophils $\left.>0.5 \times 10^{9} / 1\right)$ was achieved on $\mathrm{D}+23$. The patient remained in the $3^{\text {rd }} \mathrm{CR}$, with donor chimerism of $90-97 \%$. By the $\mathrm{D}+38$, the patient developed acute GVHD with grade 2 skin lesions responding to topical glucocorticoid therapy.

Examination on $\mathrm{D}+60$ post-transplant showed a slight neurological improvement, i.e., single movements were observed in toes, thigh muscles and legs. However, as soon as in September 2019, muscle weakness in the legs increased again up to 2 points in the proximal regions, while maintaining movements in toes, along with pelvic organ dysfunction, impaired sensitivity in the legs (mixed-type impairment with hyperaesthesia), hyperpathy up to the level of knee joints with decreased vibration sensitivity; postural tremor in the hands was more pronounced. The diagnosis was established as follows: progressive secondary complete transverse radiculomyelopathy at the Th10-L3 level, mixed origin (paraneoplastic, inflammatory, toxic, or drug-induced).

On D+70 after allo-HSCT, the immunosuppressive therapy with tacrolimus was canceled in absence of acute GVHD signs, due to decreased donor chimerism (89-91\%), persistence of poor graft function (grade 2 anemia, grade 3 thrombocytopenia), in order to promote the graft-versus-leukemia $(\mathrm{GvL})$ immunological reaction. The $3^{\text {rd }}$ bone marrow ALL relapse was diagnosed at the $\mathrm{D}+81$, as based on detection of $20 \%$ undifferentiated blasts in bone marrow, with $45 \mathrm{dim} /$ CD19-/CD10+/CD34+/CD38+/CD20-/CD22- phenotype in $28 \%$ of cells; cytogenetic aberrations $(45, \mathrm{X},-\mathrm{Y}, \mathrm{t}(5 ; 6)$ (p13; p12), t (14; 19) (q32; q13) [10] in 67\% of metaphases, further reduction of donor chimerism to $60-66 \%$. Evidence for neuroleukemia and other extramedullary lesions was not available at this time.

Since D+104 after allo-HSCT, further deterioration presented with increased ossalgia syndrome in legs and development of paralytic acute intestinal obstruction. Pulse therapy with dexamethasone $(20 \mathrm{mg})$ for 4 days and prokinetic therapy were associated with resolution of acute intestinal obstruction and some relief of pain syndrome. After cytoreductive therapy, in order to intensify immune activity of the donor graft, the donor lymphocytes were infused $\left(1.0 \times 10^{6}\right.$ $\mathrm{CD} 3+$ cells $/ \mathrm{kg})$.

Hence, this ALL case exhibited secondary relapse with refractory course of the malignant disease, early relapse after allo-HSCT, limited efficiency of therapeutic options (including targeted drugs). Therefore, nonmyeloablative cytostatic treatment was performed as a salvage therapy, according to the FLAG schedule (fludarabine, high-dose cytarabine and G-CSF). On the D+120 after first HSCT the bone marrow infusion from his mother was made (haploidentical donor, HLA-compatibility, 5/10), aiming for induction of GvL effect. Before the allo-HSCT procedure, blood counts showed profound cytopenia (grade 3 anemia, grade 4 thrombocytopenia, grade 4 neutropenia), and total bone marrow infiltration with blast cells $(94 \%)$. During the $2^{\text {nd }}$ allo-HSCT transfusion of $2.78 \times 10^{6}$ haploidentical CD34+ cells/kg was performed, i.e., by the $\mathrm{D}+4$ after second HSCT, the patient developed infectious complications (severe sepsis with multidrug-resistant Klebsiella pneumoniae) followed by septic shock and multiorgan failure. On D+6 after haplo-HSCT, the patient deceased with profound bone marrow aplasia complicated by fatal infection refractory to appropriate antibacterial therapy. Obduction and pathological assessment were not performed being declined by the relatives.

\section{Laboratory and instrumental data relevant for the myelopathy diagnostics}

CSF analysis of 14.05.2019: protein $185 \mathrm{mg} / \mathrm{l}$, cytosis 20/3 (lymphocytes 10), further analysis (3 monthly checks) showed no significant abnormalities. The neuronal immune oncomarker panel was negative. Positive IgG and negative IgM to Toxoplasma gondii in blood serum were observed. C-reactive protein (20.05): $29.9 \mathrm{mg} / \mathrm{l}(0.1-8.2)$, fibrinogen $4.46 \mathrm{~g} / \mathrm{l}$ (1.8-3.5), ferritin $2953 \mu \mathrm{g} / \mathrm{l}$ (23.9-336), vitamin B12 (06.06), $1083.6 \mathrm{pmol} / \mathrm{l}$ (133-675), vitamin B9 (06.06) 5.2 nmol (above 13.4; methotrexate, folic acid antagonist had been prescribed).

On the basis of brain MRI with contrast (24.04.2019) at the GE Signa HDxt tomograph, with magnetic field strength of 1.5 T, no evidence for volumetric masses was obtained.

MRI of the spinal cord (Siemens Magnetom Trio A Tim MR tomography, magnetic field of $3.0 \mathrm{~T}$ ) revealed infiltration of the bone marrow in vertebral bodies at L1-L5 and pelvic bones (probable sign of primary malignancy). No soft tissue masses were detected (Fig. 1).

Stimulative electroneuromyography (ENMG) revealed features of bilateral radiculopathy at L5-S1 levels, mainly on the left decreased amplitudes of M-responses of the $n$. peroneus by $51 \%$ on the right and $85 \%$ on the left side, increased residual latency to $7 \mathrm{~ms}$; increase in minimal latency of F-waves to $49-50 \mathrm{~ms}$, while retaining normal characteristics of the sensory tracts. The initial signs of demyelinating lesions of motor tracts were noted at lower extremities, with polyneuritis-like features (increase in residual latency to 5-7 ms).

Control pre-transplant MRI of lumbosacral spine was performed on June 22, 2019 (MR tomograph GE Signa HDxt, $1.5 \mathrm{~T}$ ): no signs of myelopathy were detected; no accumulation of contrast was observed.

On D+60 post-HSCT $(24.08,12$ weeks from the onset of neurological symptoms) a control MRI was made (MR tomograph GE Signa HDxt, at a magnetic field strength of 1.5 $\mathrm{T})$ of thoracic and lumbar regions with contrast, which revealed the expected intramedullary zone of the pathological MR signal in posterior spinal cord at the level from upper border of MRI scan (Th10) to the L3 vertebra, which corresponded to the pattern of myelopathy at this level (Fig. 1). In this case, it is advisable to suggest late detection of CNS damage, which is characteristic to the abovementioned diagnosis of neurological complications in oncohematological patients. 


\section{Discussion: differential diagnosis}

Management of a hematological patient with malignant diseases requires careful monitoring of neurological disorders. Exclusion of a specific CNS lesion is the first question for consulting neurologist. However, detection of leukemic foci in the immediate vicinity to neural structures does not exclude the opportunity of other etiological factors. In hematooncological patients resistant to therapy, myelopathy may be diagnosed much later than the lesions of other origins. Appropriate therapeutic factors and clinical criteria are listed in Table 1.

There are diverse potential mechanisms of spinal cord injury in this clinical setting, e.g., vascular ischemic-hemorrhagic, paraneoplastic and extensive dysmetabolic pathology, primarily associated with vitamin B12 metabolism. Autoimmune antibody-mediated mechanisms of CNS damage associated with molecular targets: aquaporin-4, myelin oligodendrocyte and myelin-associated glycoproteins (MOG, MAG) are attracting much attention [7].

In our experience, genesis of the myelopathy prior to HSCT should be also differentiated from funicular myelosis, polyradiculoneuropathy, volumic and hemorrhagic lesions, vascular ischemia, and dysmetabolic manifestations. According to MRI images of spinal cord, no clear evidence for funicular myelosis was obtained; high vitamin B12 level was found (1083.6 pmol/l), homocysteine was not assayed. Folic acid deficiency was attributed to methotrexate injections.

Development of muscular atrophy at the lower extremities required topical diagnosis of lesions of the cauda equina area. Control MR study did not confirm damage of the spinal cord before allo-HSCT. According to results of ENMG, polyneuritic genesis of amyotrophy was also excluded.

\section{Table 1. Differential criteria for the diagnosis and particularity of myelopathy in a patient with leukemia}

\begin{tabular}{|c|c|}
\hline Neurological & $\begin{array}{l}\text { - complications of endolumbal chemotherapy are characterized by persistent symptoms corresponding to } \\
\text { local lesion of the dorsal spinal cord; } \\
\text { - progression of underlying disease (neuroleukemia) is accompanied by symptoms typical to diffuse damage } \\
\text { of spinal cord (often combined with signs of spinal roots damage); } \\
\text { - in cases of previous methotrexate therapy, it is necessary to start with checking vitamin B12 in blood, since } \\
\text { myelopathy with signs of sensory ataxia may develop due to its deficiency (in } 30 \% \text { of cases) }\end{array}$ \\
\hline Hematological & $\begin{array}{l}\text { In the onset and relapse of ALL: } \\
\text { - in the onset of neurological symptoms, it is necessary to perform neuroimaging and lumbar puncture } \\
\text { (searching for blasts); } \\
\text { - when performing a diagnostic lumbar puncture, intrathecal administration of the cytostatic triplet (even in } \\
\text { the absence of neurological symptoms) is mandatory; } \\
\text { - cytostatic triplet therapy should be administered only after excluding infectious origin of the CNS lesion; } \\
\text { - further endolumbar cytostatic injections and / or radiation therapy are performed according to the selected } \\
\text { treatment protocol }\end{array}$ \\
\hline Radiological & $\begin{array}{l}\text { - complications of intrathecal chemotherapy are characterized by damage of the dorsal parts of the spinal cord; } \\
\text { - leukemic lesions (progression of the underlying disease) characterized by diffuse changes; } \\
\text { - paraneoplastic myelopathy: primarily affects the gray matter; less often - in combination with the lateral } \\
\text { and dorsal parts of spinal cord; } \\
\text { - in dysmetabolicmyelopathies and deficiency conditions, tract-specific changes are detected, most often with- } \\
\text { out the accumulation of contrast on MRI; } \\
\text { - repeated MRI is advisable } 6 \text { weeks after onset of the symptoms; } \\
\text { - MRI of } 1.5 \text { T and more is preferred; the following modes are required: T2, STIR/T2 FatSat; } \\
\text { - either accumulation of paramagnetic contrast agent, or its absence may be observed }\end{array}$ \\
\hline Laboratory & $\begin{array}{l}\text { - dysmetabolic conditions: deficiency of Vit B12/ B9/ vit E, along with lack of specific changes in cerebrospinal } \\
\text { fluid (CSF); } \\
\text { - homocysteine deficiency (in } 80 \% \text { of cases of methotrexate use); } \\
\text { - progression of the underlying disease with CNS damage based on presence of blast cells in CSF; } \\
\text { - in classical paraneoplastic myelopathy, pleiocytosis appears } 4.1 \text { months later (1 to } 7 \text { months); } \\
\text { - paraneoplastic autoantibodies are detected in } 81 \%\end{array}$ \\
\hline $\begin{array}{l}\text { Electro- } \\
\text { physiological }\end{array}$ & $\begin{array}{l}\text { - stimulation ENMG (and needle EMG) are required; } \\
\text { - evaluation of the motor and sensory tracts; } \\
\text { - magnetic stimulation with the assessment of evoked motor responses is the most sensitive electrophysio- } \\
\text { logical method for the spinal cord damage diagnostics }\end{array}$ \\
\hline Treatment & $\begin{array}{l}\text { - glucocorticosteroids are ineffective; } \\
\text { - progression of the main disease: presence of symptoms in absence of confirmed lesion by MRI; the expected } \\
\text { effect of treatment (cytostatic triplet, immunosuppressive or radiation therapy) causes reduction of neuro- } \\
\text { logical deficit }\end{array}$ \\
\hline
\end{tabular}


Tumor cell infiltration of pericentral area of spinal channel or (less likely) radiculus before forming of spinal nerves may be another possible cause of increasing neurological deficit. According to MRI of the pelvic organs with contrast and post-contrast (dynamic) regimens, we have still excluded venous ischemia or secondary compression of spinal cord by adjacent organs due to progression of the underlying disease.

Diffuse affection of the spinal cord is more typical to hematological malignancies than spinal metastatic lesions [8]. Despite lacking MRI evidence on the spinal cord injury, an impression still remained on ALL relapse as the most probable reason for these changes. The limitations of MRI resolution at this stage of morphological changes prevented detection of minimal spinal cord damage, which required MRI of thoracic and lumbar spine with contrast, or repeated PET visualization.

Vertebrogenic changes were excluded by MRI examination. Postradiation myelitis was also unlikely, since this area was not covered by the irradiation fields.

Complications from lumbal puncture. Development of myelopathy occurs in 3\% of cases after triplet drug administration. Clinical manifestations of neurotoxicity can be variable: meningeal syndrome, epileptic seizures, encephalopathy, paraplegia, or even quadriplegia $[9,10]$. Cases of myelopathy after a single endolumbar administration of methotrexate and cytarabine have been described in the literature [11]. The mechanism of CNS damage by chemotherapy is not completely clear. One theory suggests genetic predisposal for these events (gene polymorphisms of folate-metabolizing enzymes and apolipoprotein E) [12]. In our clinical case, endolumbar administration of the triplet therapy was performed continuously (about 30-40 times), with signs of spinal cord injury appearing beyond the early post-puncture period.

Destruction of the spinal cord caused by diffuse macrophage infiltration has been described as a cause of myelopathy in a patient with blast plasmacytoid neoplasm originating from dendritic cells, when the intrathecal infusion of methotrexate/cytarabine was administered. Most often, the syndrome is acute and is initially detected by MRI with a increased amount of protein in CSF [13]. In our case, the symptoms developed progressively, and protein was not detected in CSF. Moreover, according to MRI, myelopathy was not detected in debut of clinical manifestations.

Neurotoxic genesis of myelitis in targeted therapy. According to a report by the European Committee for Medicinal Products for Human Use (2017), neurotoxicity of inotuzumab ozogamycin is limited by $2 \%$ of cases. Peripheral sensory polyneuropathy at a grade $<3$ is the most severe neurological complication observed with this drug [14].

MOG-associated myelitis. In addition to selectins, CD22 and sialoadhesin are the only well characterized adhesion molecules dependent on sialic acid. CD22 is a member of the immunoglobulin superfamily, which is expressed by B-lymphocytes and sialoadhesin - by the macrophage receptor. Cloning of the gene encoding sialoadhesin has shown that it is also similar to immunoglobulin. Both proteins have a sequence similarity to myelin-associated glycoprotein (an oligodendrocyte and Schwann cell adhesion molecule that is involved in the myelination process) [15].

The experience of using inotuzumab ozogamycin at the MD Anderson Cancer Center demonstrates development of neuroleukemia with anti-CD22 therapy, which indirectly confirms inability to penetrate the blood-brain barrier [16] and cannot be a cause of myelopathy.

Paraneoplastic myelopathy (PM). Both tumor cells with the presence of intranuclear or cytoplasmic antigens and protein antigens of synaptic and subsynaptic levels are considered as targets for damage [17]. Immunological tissue damage in autoimmune encephalitis corresponds to types II (antibody-dependent cytotoxicity) and IV (mediated by T-cell cytotoxicity), according to the classification of P. Gell and R. Coombs [18].

In general, epidemiology of paraneoplastic neurological complications, paraneoplastic myelopathy occurs in $6.5 \%$ of cases [19]. PM is characterized by a gradual onset over 16.5 months (1.5-49 months), with no improvement in patients' clinical condition. The most typical age is 46-71 years [20]. In the case considered in this article, a reduction in neurological deficit was observed 2.5 months after allo-HSCT, and onconeuronal antibodies were not detected. Only time parameter for achieving paraplegia (within 6 months of onset) was met among all known criteria.

It should be noted that there are no accurate data on myelopathies in the oncohematological patients. In addition, presence of a massive pharmacotherapeutic history did not allow to suggest a classical paraneoplastic myelopathy.

Progression of the underlying disease, i.e., infiltration of spinal cord with blast cells. Given the extent of the lesion in second relapse involving intra-abdominal lymph nodes, testicles, and detection of lymphoblasts in the cerebrospinal fluid, infiltration of spinal cord by blast cells could be another probable cause of neurological deficits in the patient.

In general, neuroimaging methods do not exhibit highest sensitivity when searching cancer manifestations. According to Chamberlain M., the sensitivity of MRI in leukemia does not exceed 44\% [21]. A number of studies have shown that the frequency of a false-negative MRI in B-ALL reaches 60$65 \%$ and $10 \%$ in false-positives. These data limit the use of MRI as a distinct diagnostic tool, and MRI does not always provide a reliable answer about absence of CNS damage in ALL [22]. Development of later becoming negative neurological symptoms in the patient (paralytic acute intestinal obstruction) upon third relapse and relief of this condition after pulse therapy with dexamethasone confirms its connection with myelitis detected by repeated MRI.

\section{Conclusion}

In the patients with ALL (up to $30 \%$ of all acute leukemias in adults), myelopathy occurs in less than $10 \%$, still remaining an underestimated complication [23]. There may be diverse reasons for development of neurological symptoms in patients with resistant and prolonged course of ALL, i.e., toxic 
effects of chemotherapy (systemic, endolumbar), effects of radiation therapy, neuroleukemia (CNS infiltration with blast cells), infectious complications or tumor compression. Chemical (aseptic) arachnoiditis, myelopathy and leukoencephalopathy, as the most common complications associated with chemotherapy (especially, after endolumbar injections of methotrexate and cytarabine) are more common in children [24, 25]. However, increasing life expectancy among ALL patients led to increased incidence of myelopathy in adult patients as well [26]. Radiation therapy, according to current data, causes myelopathy at a frequency of $0.03-0.2 \%$ in the cancer group $[27,28]$, although two decades ago it was estimated at $0.5 \%$ [29]. Accumulation of data on spinal complications when using targeted therapy is in progress.

Therefore, modern treatment of oncohematological patients employs wide range of drugs and methods, which can potentially cause neurotoxic effects. Nevertheless, along with getting information on the drugs used, the first issue is to make differential diagnosis with progression of the primary malignancy.

Myelopathy after intrathecal chemotherapy is a rare complication, but the triplet contains methotrexate, which may lead to decreased levels of folic acid in the blood [30], an indirect factor of funicular myelosis variant, also representing a potential side effect of therapies applied at subsequent stages of treatment. Thus, the genesis of myelopathy in this clinical case may have at least 3 explanations: dysmetabolic, toxic and radiculus' cell infiltration with secondary ischemia.

Assessment of cellular and biochemical composition of cerebrospinal fluid, MRI examination of CNS remain the main methods for diagnosing various neurological complications in ALL patients. However, due to low diagnostic sensitivity of neuroimaging, further research is required to standardize these procedures and ensure optimal clinical interpretation of their results. When using available MRI monitoring, one should adhere the time points upon follow-up of the patients in order to increase their diagnostic efficiency. In the group of patients with hematological diseases, this follow-up period may be about 1.5-2.5 months after the onset of a neurological complication, in this case, myelopathy.

\section{Conflict of interest}

The study was not sponsored. The authors are responsible for submitting the final version of the manuscript to print. All authors took part in developing the concept of the article and writing the manuscript. The final version of the manuscript was approved by all authors. The case was prepared based on CARE guidelines.

\section{References}

1. Alakel N, Stölzel F, Mohr B. Kramer M, Oelschlägel U, Röllig C, Bornhäuser M, Ehninger G, Schaich M. Symptomatic central nervous system involvement in adult patients with acute myeloid leukemia. Cancer Manag Res. 2017;9:97102. doi: 10.2147/CMAR.S125259

2. Frishman-Levy L, Izraeli, S. Advances in understanding the pathogenesis of CNS acute lymphoblastic leukaemia and potential for therapy. Br J Haematol. 2017;176(2):157-167. https://doi.org/10.1111/bjh.14411

3. Joseph P, Reyes M. Dorsal column myelopathy following intrathecal chemotherapy for acute lymphoblastic leukemia. J Spinal Cord Med. 2014 Jan;37(1):107-13. doi:10.1179/2045 $\underline{772312 Y .0000000081}$

4. Beh SC, Greenberg BM, Frohman T, Frohman E.M. Transverse myelitis. Neurol Clin. 2013; 31(1):79-138. doi: 10.1016/j.ncl.2012.09.008

5. Xing L, Wen S, Niu Z, Wang F, Zhang X. Rituximab for acute demyelinating myelopathy after allogeneic hematopoietic stem cell transplantation: a case report. Postgrad Med. 2020; 1-4. doi: 10.1080/00325481.2020.1736884

6. Parovichnikova EN, Klyasova GA, Troitskaya VV, Sokolov AN, Kuzmina LA, Mendeleeva LP, Kravchenko SK, Ryzhko BB, Bondarenko SN, Karyakina EA, et al. Efficiency of treatment of adult patients with acute T-lymphoblastic leukemia according to the ALL-2009 protocol of the Russian Acute Leukemia Study Group. Ter Arch. 2013 85(8):2934. (In Russian). https://ter-arkhiv.ru/0040-3660/article/ view/31297

7. Hartung HP, Rieckmann P. Pathogenesis of immune-mediated demyelination in the CNS. J Neural Transm Suppl. 1997;50:173-181. doi: 10.1007/978-3-7091-6842-4_17

8. Kim HJ, Ryu KN, Choi WS, Choi BK, Choi JM, Yoon Y. Spinal involvement of hematopoietic malignancies and metastasis: differentiation using MR imaging. Clin Imaging 1999; 23(2):125-133. doi: 10.1016/s0899-7071(99)00105-9

9. Nguyen T, Palacio A, Beuret-Blanquart F. Paraplegia after intrathecal injection of Methotrexate. Ann Phys Rehab Med. 2011; 54S: e162-e167. doi: 10.1016/j.rehab.2011.07.513

10. Pan Y, Wang C, Wang H, Tao Q, Xiong S, Zhai Z. Transverse myelopathy occurring with intrathecal administration of methotrexate and cytarabine chemotherapy: A case report. Oncol Lett.2016; 11: 4066-4068, 2016. doi: 10.3892/ $\underline{\mathrm{ol} .2016 .4519}$

11. Lee HY, Sung-il I, Myoung-Hee Kang, Im S-il, Kang M-H, Kim KM, Kim SH, Kim H-G, Kang JH, Lee G-W. Irreversible paraplegia following one time prophylactic intrathecal chemotherapy in an adult patient with acute lymphoblastic leukemia. Yonsei Med J. 2008; 49(1):151-154. doi: 10.3349/ ymj.2008.49.1.151

12. Froklage FE, Reijneveld JC, Heimans JJ. Central neurotoxicity in cancer chemotherapy: pharmacogenetic insights. Pharmacogenomics. 2011; 12(3):379-395. doi: 10.2217/ pgs.10.197

13. Dornbos D 3rd, Elder J, Otero J Baiocchi RA, Slone HW, Puduvalli VK, Giglio P. Spinal cord toxicity from intrathecal chemotherapy: a case with clinicopathologic correlation. World Neurosurg. 2019; 128:381-384. doi: 10.1016/j. wneu.2019.05.123

14. EMA/289046/2017 Committee for Medicinal Products for Human Use, CHMP. https://www.ema.europa.eu/en/ news/meeting-highlights-committee-medicinal-productshuman-use-chmp-18-21-april-2017 
15. Kelm S, Pelz A, Schauer R, Filbint MT, Tang S, de Bellard ME, Schnaar RL, Mahoney JA, Hartnell A, Bradfield P, Crocker PR. Sialoadhesin, myelin-associated glycoprotein and CD22 define a new family of sialic acid-dependent adhesion molecules of the immunoglobulin superfamily. Curr Biol. 1994; 4(11):965-972. doi: 10.1016/s0960-9822(00)00220-7

16. Kantarjian H, Thomas D, Jorgensen J, Kebriaei P, Jabbour E, Rytting M, York S, Ravandi F, Garris R, Kwari M, et al. Results of Inotuzumab Ozogamicin, a CD22 monoclonal antibody in refractory and relapsed acute lymphocytic leukemia. Cancer. 2013; 119(15): 2728-2736. doi:10.1002/cncr.28136

17. Vincent A. Developments in autoimmune channelopathies. Autoimmun Rev. 2013; 12(6):678-681. doi: 10.1016/j. autrev.2012.10.016

18. Rajan TV. The Gell-Coombs classification of hypersensitivity reactions: a re-interpretation. Trends Immunol. 2003; 24(7):376-379. doi: 10.1016/s1471-4906(03)00142-x

19. Giometto B, Grisold W, Vitaliani R, Graus F, Honnorat J, Bertolini G, PNS Euronetwork. Paraneoplastic neurologic syndrome in the PNS Euronetwork database: A European study from 20 centers. Arch. Neurol. 2010; 67:330-335. doi: 10.1001/archneurol.2009.341

20. Liu Z, Jiao L, Qiu Z, Da Y Tanga Y, Lina Y, Lia D, Huangb J, Kangb X, Donga H. Clinical characteristics of patients with paraneoplastic myelopathy. J Neuroimmunol. 2019; 330:136142. doi: 10.1016/j.jneuroim.2019.03.001

21. Chamberlain MC, Sandy AD, Press GA. Neurology. Leptomeningeal metastasis: a comparison of gadolinium-enhanced MR and contrast-enhanced CT of the brain. Neurology. 1990; 40(3 Pt 1):435-438. doi: 10.1212/wnl.40.3 part 1.435

22. Del Principe MI, Maurillo L, Buccisano F, Sconocchia G, Cefalo M, De Santis G, Di Veroli A, Ditto C, Nasso D, Postorino $\mathrm{M}$, et al. Central nervous system involvement in adult acute lymphoblastic leukemia: diagnostic tools, prophylaxis, and therapy. Mediterr J Hematol Infect Dis. 2014; 6(1):e2014075. doi: 10.4084/MJHID.2014.075

23. Thomas $\mathrm{X}$, Le Q. Central nervous system involvement in adult acute lymphoblastic leukemia. Hematology 2008;13(5):293-302. doi: 10.1179/102453308X343374

24. Skullerud K, Halvorsen K. Encephalomyelopathy following intrathecal methotrexate treatment in a child with acute leukemia. Cancer. 1978; 42:1211-1215. doi: 10.1002/1097-0142(197809)42:3<1211::aid-cncr2820420326>3.0.c0;2-x

25. Cachia D, Kamiya-Matsuoka C, Pinnix CC, Chi L, Kantarjian HM, Cortes JE, Daver N, Woodman K. Myelopathy following intrathecal chemotherapy in adults: a single institution experience. J Neurooncol. 2015; 122(2): 391-398. doi: $10.1007 / \mathrm{s} 11060-015-1727-\mathrm{z}$

26. Yong Lee H, Im S, Kang M-H, Kim KM, Kim SH, Kim H-G, Kang JH, Lee G-W. Irreversible paraplegia following one time prophylactic intrathecal chemotherapy in an adult patient with acute lymphoblastic leukemia. Yonsei Med J. 2008; 49(1):151-154. doi: 10.3349/ymj.2008.49.1.151
27. Schultheiss TE. The radiation dose-response of the human spinal cord. Int J Radiat Oncol Biol Phys 2008; 71:14551459. doi: 10.1016/j.ijrobp.2007.11.075

28. Wong CS, Fehlings MG, Sahgal A. Pathobiology of radiation myelopathy and strategies to mitigate injury. Spinal Cord 2015; 53(8):574-580. doi: 10.1038/sc.2015.43

29. Wong CS, Van Dyk J, Milosevic M, Laperriere NJ. Radiation myelopathy following single courses of radiotherapy and retreatment. Int J Radiat Oncol Biol Phys. 1994; 30(3):575-581. doi: 10.1016/0360-3016(92)90943-c

30. Krasnov VS, Bedenko AS, Totolyan NA, Skoromets AA. Longitudinally extensive transverse myelitis associated with intrathecal synthesis of oligoclonal immunoglobulin $\mathrm{G}$ and with vitamin B12 deficiency. Neurology, neuropsychiatry, psychosomatics. 2016;8(3):71-75 (In Russian). https://doi.org/10.14412/2074-2711-2016-3-71-75 


\title{
| Дифференциальная диагностика миелопатии у пациента с рецидивирующим острым лимфобластным лейкозом
}

\author{
Алексей Ю. Полушин ${ }^{1}$, Ксения С. Афанасьева ${ }^{1}$, Белла И. Аюбова ${ }^{1}$, Сергей Н. Бардаков ${ }^{2}$, Дмитрий И. Скулябин ${ }^{2}$, \\ Андрей О. Агафонов ${ }^{1}$, Ольга В. Сергиеня ${ }^{3}$, Ярослав Б. Скиба ${ }^{1}$, Владимир С. Краснов ${ }^{1}$, Михаил М. Канунников ${ }^{1}$, \\ Татьяна А. Рудакова ${ }^{1}$, Анна Г. Смирнова ${ }^{1}$, Сергей Н. Бондаренко ${ }^{1}$, Мария Д. Владовская ${ }^{1}$, Иван С. Моисеев ${ }^{1}$, \\ Александр Д. Кулагин ${ }^{1}$ \\ ${ }^{1}$ Первый Санкт-Петербургский государственный медицинский университет им. И. П. Павлова, Санкт-Петербург, \\ Россия \\ ${ }^{2}$ Военно-медицинская академия им. С. М. Кирова, Санкт-Петербург, Россия \\ ${ }^{3}$ Научный медицинский исследовательский центр им. В. А. Алмазова, Санкт-Петербург, Россия
}

\section{Резюме}

Лейкоз-ассоциированная миелопатия является редким, но недооцененным осложнением интенсивной терапии злокачественных новообразований. Его этиология разнообразна и может возникать как на фоне основного заболевания, так и его интенсивной терапии лечения. Миелит требует проведения дифференциальной диагностики между фуникулярным миелозом и другими дисметаболическими состояниями, полирадикулоневропатиями, объемными образованиями, геморрагическими и ишемическими поражениями ЦНС. В то же время миелопатия может выступать в качестве нежелательного явления применения лучевой или таргетной терапии, цитостатиков. Также данное состояние требует проведения дифференциальной диагностики с паранеопластическим поражением спинного мозга или прогрессией основного заболевания. Диагностика миелопатии достаточно сложна и выявление ее при помощи нейровизуализационных методик может быть отсрочено относительно дебюта неврологической симптоматики.
Мы представляем клинический случай миелопатии у пациента 31 года с диагнозом острого лимфобластного лейкоза, которая была доказана через 2,5 месяца от возникновения характерных неврологических проявлений. В статье также представлены клинические, лабораторные и инструментальные критерии и особенности миелопатии, ассоциированной с лейкозом.

\section{Ключевые слова}

Нейролейкоз, острый лимфобластный лейкоз, аллогенная трансплантация гемопоэтических клеток, неврологические осложнения, миелопатия, МРТ, дифференциальная диагностика, таргетная терапия. 